\title{
Konsep Kepribadian Anak yang Shalihah dalam Kitab Al Akhlaq Lil Banat
}

\author{
Ulin Nadlifah Ummul Khoir \\ SMPN 1 Bawen Kabupaten Semarang \\ Email: ulina@gmail.com
}

\begin{abstract}
Abstrak
Akhlak mulia merupakan cerminan dari kepribadian seseorang, selain moralitas unggul akan dapat membawa seseorang ke martabat yang tinggi. Akhir-akhir ini, akhlak yang baik adalah barang mahal dan sulit ditemukan. Membentuk pribadi berakhlak mulia harus ditanamkan paada anak sejak usia dini, karena pembentukannya akan lebih mudah daripada setelah anak tumbuh dewasa. Buku Al-Akhlaq lil Banat membahas beberapa akhlak untuk diterapkan dalam kehidupan, lingkungan keluarga yang baik, sekolah atau masyarakat. Hal ini akan membentuk pribadisantun sesuai dengan petunjuk Al Qur'an. Penelitian ini adalah kajian literatur. Untuk mendapatkan data yang representatif digunakan studi pustaka untuk mencari, mengumpulkan, membaca, dan menganalisa buku-buku yang ada relevansinya dengan masalah penelitian. Untuk mencapai keberhasilan dalam proses pendidikan, materi dalam buku alAkhlaq lil Banat dapat digunakan sebagai referensi untuk mencapai keberhasilan pendidikan. Materi yang disajikan dalam buku ini tidak hanya mengacu pada hubungan antara manusia dan Tuhan (transendental), tetapi juga pada hubungan antara manusia (antroposentris), seperti moralitas kepada orang tua, saudara, tetangga, teman sebaya dan juga untuk adab atau tata cara, sopan santun seperti mengunjungi, berjalan, bepergian, dan sebagainya.
\end{abstract}

Noble character is a reflection of one's personality, in addition to the superior morality will be able to bring someone to the high dignity. Lately, a good manner is costly and hard to find. To form a noble 
personal, moral cultivation against children should be encouraged from an early age, since its formation will be easier than after the child's adulthood. Al-Akhlaq lil Banat book discusses some manners to apply in life, good family environment, school or community. It will create private-mannered accordance with the guidance of the Qur'an. It is a kind of literature review. To obtain representative data in the discussion, it is used library research to find, collect, read, and analyze the books with no relevance to the research problem. To achieve success in the educational process, the material in the book al-Akhlaq lil Banat can be used as a reference in order to achieve educational success. The material presented in this book is not only refers to the relationship between man and God (transcendental), but also on the relationship between humans (anthropocentric), such as morality to parents, relatives, neighbors, peers and also to the adab or ordinances, such manners visit, walking, traveling, and so forth.

Kata kunci: konsep pendidikan Islam, al-Akhlaq lil Banat, pribadi shalihah

\section{Pendahuluan}

Sesungguhnya anak adalah amanah Allah yang perlu kita syukuri, "Jika amanah itu disia-siakan, maka tunggulah saat kehancuran" (Jamal Abdurrahman, Terj. Ardianingsih, 2003: v). Pengertian anak bukan sekedar yang terlahir dari tulang sulbi kita atau anak cucu keturunan kita saja, namun juga anak seluruh orang muslim di manapun mereka berada, atau berasal dari bangsa manapun yang menjadi tumpuan harapan kita, untuk dapat mengembalikan kesatuan umat seutuhnya, sebagaimana dalam Qs. al-Mukminun: 52:

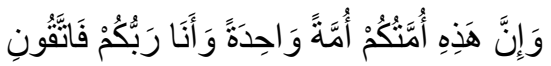

Artinya: "Dan sesungguhnya (agama Tauhid) ini, adalah agama kaтu sетиa, agama yang satu" 
Anak laki-laki adalah sumber dari kepayahan yang dirasakan oleh para orang tua, sedangkan anak perempuan adalah sosok manusia yang paling lemah, dan rentan menimbulkan fitnah. Ada pula yang menyebutkan perempuan adalah sejenis makhluk dari jenis manusia yang halus kulitnya, lemah tulangnya, lembut suaranya dan agak berlainan bentuk dan susunan tubuhnya dari kaum laki-laki. Dari perbedaan bentuk dan kondisi antara laki-laki dan perempuan tersebut, Allah bermaksud untuk membedakan pola hidup dan cara hidup antar laki-laki dan perempuan karena dari perbedaan tersebut terkandung hikmah yang sangat besar bagi manusia.

Anak perempuanlah yang membuat para ayah mencucurkan keringat dalam mendidiknya, bahkan harus bersikap lemah lembut dalam mendidik, akan tetapi setelah menginjak dewasa, diri mereka mengalami perubahan drastis. Perubahan tersebut banyak dipengaruhi oleh sosialbudaya tempat ia berada. Apalagi di era modern ini sosok perempuan sudah mulai tampil mendampingi atau menyamai bahkan melebihi kiprah kaum laki-laki. Begitu banyak penyalahgunaan kelebihan yang dimiliki wanita menjadikan sebagai satu sarana untuk mencapai satu tujuan yang semu. Kehadiran wanita dalam kancah kehidupan modern telah memberi gambaran yang semakin berantakan dalam pandangan Islam. Gaya hidup dan penampilan wanita seakan sudah sangat mirip dengan laki-laki, mereka seolah sudah lupa akan hakikatnya sebagai kaum hawa, khususnya dalam pergaulan.

Ketika seorang gadis bergaul dengan sesamanya di dalam sebuah lingkungan, terkadang ia terpana melihat suatu perilaku yang dilakukan 
oleh temannya padahal perilaku tersebut jauh dari nilai-nilai yang benar, oleh karena itu kita wajib mengingatkan akan hal ini. Maka akidah Islam yang luruslah yang diperlukan untuk membentuk mereka menjadi sosok yang shalihah. Pendidikan Islam bukanlah untuk membentuk sosok pribadi lain di luar kepribadian manusia, tetapi justru membantu manusia untuk menemukan jati dirinya sebagai manusia muslim yang beriman dan bertaqwa. Oleh karena itu program utama dan perjuangan pokok dari suatu usaha pendidikan adalah pembinaan akhlak yang baik yang harus ditanamkan sejak dini pada anak. Hal ini sesuai dengan hadis Rasulullah yang artinya "Muliakanlah anak-anak kalian dan didiklah budi pekerti yang luhur" (HR. Ibnu Majah).

Seseorang akan dinilai bukan karena jumlah materinya yang melimpah, ketampanan wajahnya dan bukan pula karena jabatannya yang tinggi. Allah SWT akan menilai hamba-Nya berdasarkan tingkat ketakwaan dan amalnya. Seseorang berakhlak mulia akan cenderung dihormati oleh masyarakat karena setiap orang di sekitarnya merasa tenteram dengan keberadaannya dan orang tersebut menjadi mulia di lingkungannya. Untuk membangun akhlak mulia di dalam masyarakat diperlukan pendidikan yang baik dan terarah. Keterkaitan antara akhlak dan pendidikan sangatlah erat sekali, pendidikan merupakan pengetahuan yang terserap oleh peserta didik sedangkan akhlak merupakan pengaruh dari pendidikan itu sendiri. Namun tidak jarang masyarakat mendidik anak-anak khususnya usia sekolah dasar memaksakan kehendaknya tanpa mempertimbangkan dampak dari pemaksaan pendidikan itu sendiri. Padahal memberikan pemahaman dan keyakinan akan pentingnya akhlak 
bagi anak membutuhkan suatu metode penyampaian agar anak atau peserta didik menganggap itu merupakan suatu kebutuhan. Sehingga proses internalisasi dapat berjalan dengan baik, anak mampu menerima konsep akhlak dengan baik serta mampu mengaplikasikan dalam keseharian. Perlu materi dan metode yang tepat dan mudah digunakan oleh orang tua, masyarakat dan khususnya warga pendidikan.

Jadi jelaslah bahwa betapa pentingnya pembinaan akhlak pada anak terutama anak perempuan demi tercapainya kesejahteraan dan kebahagiaan hidup, baik dunia maupun akhirat. kitab al-Akhlaq lil Banat merupakan sebuah kitab pegangan yang digunakan oleh beberapa lembaga pendidikan islam di Indonesia, kitab tersebut sangatlah urgen dalam proses pembinaan akhlak. Jika kitab ini dijadikan panduan pada banyak lembaga pendidikan islam di Indonesia, maka dapat dimungkinkan akan lahir generasi Islam yang yang berkualitas yang sesuai dengan tujuan Pendidikan Islam. Berdasar fenomena di atas, maka penulis tertarik untuk lebih mendalami lagi dalam mengkaji tentang "Konsep Pendidikan Islam dalam Membentuk Pribadi Anak yang Shalihah (Menurut Umar Bin Ahmad Baradja dalam Kitab al-Akhlaq lil Banat).

Rumusan permasalahan yang didapat dari uraian yaitu bagaimana konsep akhlak menurut Umar bin Ahmad Baradja dalam kitab al-Akhlaq lil Banat, Apakah relevansi pemikiran Umar bin Ahmad Baradja dalam kitab tersebut dalam konteks pendidikan Islam di Indonesia? 


\section{Metode Penelitian}

Penelitian ini menggunakan metode Library Research atau penelitian kepustakaan (Hadi, 1991: 9), yaitu bahwa bahan-bahan atau data-data penelitian ini diperoleh dari penelitian buku-buku dan literaturliteratur yang berkenaan dengan topik yang sedang dibahas. Sumber data yang digunakan berasal dari sumber data primer dan data sekunder.

Sumber data primer yaitu sumber data yang langsung berkaitan dengan obyek riset (Tahzidulum Dharaha, 1989: 60), dalam hal ini peneliti menggunakan kitab al-Akhlaq lil Banat. Sedangkan Sumber data sekunder yaitu sumber data yang mengandung dan melengkapi sumber data primer. Sumber data sekunder yang digunakan dalam penelitian ini adalah referensi selain kitab al-Akhlaq lil Banat yang berkaitan dengan penelitian ini.

\section{Pembahasan}

\section{Riwayat Hidup Umar Bin Ahmad Baradja}

Umar bin Ahmad Baradja lahir di kampung Ampel Magfur kota Surabaya pada tanggal 10 Jumadil Akhir $1331 \mathrm{H}$, yang bertepatan dengan 17 Mei 1913 M. Sejak kecil beliau diasuh dan dididik oleh kakeknya dari pihak ibu, yang bernama Syaikh Hasan bin Muhammad Baradja, yang merupakan ulama ahli ilmu dan fiqih. Silsilah nasab Umar berasal dari kota Saiwoon Hadromaut Yaman, nenek moyang beliau yang ke-18 bernama Syaikh Sa'ad, yang dijuluki (laqob) Abi Roja', silsilah keturunan tersebut bermuara kepada Nabi Muhammad SAW dari keturunan ke-5 yang bernama Kilab bin Murroh. Umar wafat dalam usia 
77 tahun, tanggal 16 Robiul Tsani $1414 \mathrm{H}$ atau 3 November $1990 \mathrm{M}$ di Surabaya. Jenazahnya disholatkan di Masjid Agung Sunan Ampel dan diimami oleh putranya sendiri yang menjadi khalifah (penggantinya) yaitu al-Ustadh Ahmad bin Umar Baradja (al-Kisah, 2007: 85-89).

Umar bin Ahmad Baradja muda menekuni ilmu agama dan bahasa arab. Beliau mengenyam pendidikan di Madrasah al-Khairiyah di kampung Ampel Surabaya, sebuah sekolah yang berdasarkan Islam Ahlu Sunnah wal Jamaah dan bermazdhabkan Syafi'i. Guru-guru beliau yang berada di Indonesia diantaranya al-Ustadh Abd Kadir bin Ahmad Bilfagih (Malang), al-Ustadh Muhammad bin Husein Ba'abud (Lawang), al-Habib Abd Kadir bin Hadi Assegaf (Surabaya), al-Habib Muhammad bin Achmad Assegaf (Surabaya), al-Habib Alwi bin Abdullah Assegaf (Solo), al-Habib Achmad bin Alwi Aldjufri (Pekalongan), al-Habib Ali bin Husein bin Syahab (Gresik), al-Habib Zein bin Abdullah Alkaff (Gresik), al-Habib Achmad bin Ghalib Alhamid (Surabaya), al-Habib Alwi bin Muhammad Al Muhdhar (Bondowoso), al-Habib Abdullah bin Hasan Maulahela (Malang), al-Habib Hamid bin Muhammad As Sery (Malang), Syeikh Robaah Hussanah al-Kholili (Palestina), Syeikh Muhammad Mursidi (Mesir), al-Habib Alwi bin Abbas al-Maliki (Makkah), al-Sayyid Muhammad Amin al-Quthbi (Makkah), al-Syeikh Muhammad Seif Nur (Makkah), al-Syeikh Hasan Muhammad alMasyssyaath (Makkah), al-Habib Alwi bin Salim Alkaff (Makkah), alSyeikh Muhammad Said al-Hadrawi al-Makky (Makkah), al-Habib Muhammad bin Hadi Assegaf (Yaman), al-Habib Abdullah bin Ahmad al-hadlar (Yaman), al-Habib Hadi bin Ahmad Alhadlar (Yaman), al- 
Habib Abdullah bin Thahir al-Haddad (Yaman), al-Habib Abdullah bin Umar al-Syathiri (Yaman), al-Habib Hasan bin Ismail bin Syeikhbubakar (Yaman), al-Habib Ali bin Zein al-Hadi (Yaman), al-Habib Alwi bin Abdullah bin Syahab (Yaman), al-Habib Abdullah bin Hamid Assegaf (Yaman), al-Habib Muhammad bin Abdullah AlHaddar (Yaman), alHabb Ali bin Zain Bilfagih (Uni Emirat Arab), al-Syeikh Muhammad Bakhith al-Muthi'i (Mesir), Sayyidi Muhammad al-Fatih al-Kattani (Maroko), Sayyidi Muhammad al-Muntashir al-Kattani (Maroko), alHabib Alwi bin Thohir al-Haddad (Malasia), Syeikh Abdul 'Alim alShidiqi (India), Syeih Hasannain Muhammad Makhluf (Mesir), al-Habib Abdul Kadir Bin Ahmad Assegaf (Saudi Arabia).

Ilmu-ilmu yang beliau kuasai diantaranya adalah bahasa dan sastra arab, ilmu tafsir dan hadis, ilmu fiqih dan tasawuf, ilmu sirrah dan tarikh. Beliau juga sedikit menguasai bahasa Belanda dan Inggris.

\section{Kultur Sosial Umar bin Ahmad Baradja}

Umar bin Ahmad Baradja dikenal sebagai sosok pribadi yang sosialis. Salah satu gerakan sosialnya adalah mencarikan dana untuk kebutuhan para janda, fakir miskin, yatim piatu, dan para santrinya. Dalam membentuk generasi yang baik dan shalih, beliau bersama alHabib Idrus bin Umar Alaydrus, menjodohkan wanita-wanita muslimah dengan pemuda muslim yang baik sekaligus mengusahakan biaya perkawinannya. Salah satu karya monumentalnya adalah membangun masjid al-Khoir Danakarya I Surabaya tahun 1971 bersama K.H. Adnan Chamim, setelah mendapat petunjuk dari al-Habib Sholih bin Muhsin 
Alhamid (Tanggul) dan al-Habib Zain bin Abdullah Alkaf (Gresik). Masjid ini sekarang digunakan untuk berbagai aktivitas yang berkaitan dengan dakwah masyarakat Surabaya.

\section{Kiprah Dakwah Umar bin Ahmad Baradja}

Awal karirnya adalah mengabdi di Madrasah al-Khairiyah Surabaya tahun 1935 sampai 1945, beliau berhasil mencetak beberapa ulama/asatidz yang telah menyebar ke berbagai pelosok tanah air. Murid beliau di antaranya; al-Ustadh Ahmad bin Hasan Assegaf, al-Habib Umar bin Idrus al-Masyhur, al-Ustadh Ahmad bin Ali Bebgei, al-Habib Idrus bin Hud Assegaf, al-Habib Hasan bin Hasim al-Habsyi, al-Habib Hasan bin abdul Kadir Assegaf, al-Ustadh Ahmad Dzaki Ghufron dan al-Ustadh Ja'far bin Agil Assegaf. Setelah beliau mengabdi di Madrasah alKhairiyah Bondowoso, beliau lalu pindah mengajar di madrasah alArabiyyah al-Islamiyyah Gresik. Setelah itu, tahun 1951-1957 beliau memperluas serta membangun lahan baru bersama dengan al-Habib Zein bin Abdullah Alkaff, sehingga wujudlah Gedung Yayasan Badan Wakaf yang diberi nama Yayasan Perguruan Islam Malik Ibrahim.

Selain mengajar di lembaga pondok beliau juga mengajar di rumahnya dan majlis taklim/pengajian. Karena sempitnya tempat dan banyaknya murid, maka beliau berusaha mengembangkan pendidikan itu dengan mendirikan Yayasan Perguruan Islam atas nama beliau al-Ustadh Ahmad Baradja, Hal ini sebagai wujud nyata dari hasil pendidikan dan pengalaman yang telah beliau dapat selama 50 tahun, dan berjalan 
sampai sekarang ini di bawah asuhan putranya yaitu al-Ustadh Ahmad bin Umar Baradja.

\section{Kepribadian Umar bin Ahmad Baradja}

Penampilan Umar bin Ahmad Baradja sangat bersahaja, juga dihiasi sifat-sifat ketulusan niat dan keikhlasan dalam segala amal perbuatan duniawi dan ukhrawi. Beliau juga menjabarkan akhlak ahlul bait, keluarga Nabi dan para sahabat, yang mencontoh baginda Nabi Muhammad SAW. Beliau tidak suka membangga-banggakan diri, baik tentang ilmu, amal, maupun ibadah sebagai perwujudan sifat tawadhunya.

Dalam buku Kunjungan Habib Alwi Solo kepada Habib Abu

Bakar Gresik, catatan Habib Abdul Kadir bin Hussein Assegaf menyebutkan, “... kami (rombongan Habib Alwi al-Habsyi) berkunjung ke rumah Syeikh Umar bin Ahmad Baradja (Surabaya). Kami dengar saking senangnya, ia sujud syukur di kamar khususnya. Ia meminta Sayyidi Alwi untuk membacakan doa dan fatihah" (al-Kisah, 2007: 8589). Sifat wara'nya sangat tinggi, perkara yang meragukan dan subhat beliau tinggalkan, sebagaimana meninggalkan perkara-perkara yang haram. Beliau juga selalu berusaha berpenampilan sederhana. Sifat Ghirah Islamiyah (semangat membela Islam) dan iri dalam beragama sangat kuat dalam jiwanya. Konsistensinya dalam menegakkan amar ma'ruf nahi munkar, misalnya dalam menutup aurat, khususnya aurat wanita, dia sangat keras dan tak kenal kompromi. Dalam membina anak 
didiknya, pergaulan bebas antara laki-laki dan perempuan beliau tolak keras.

\section{Konsep Akhlak Dalam Kitab al-Akhlaq lil Banat}

Kitab al-Akhlaq lil Banat terdiri dari tiga jilid, selebihnya akan kami paparkan kandungan dari kitab tersebut agar dapat kita pahami dengan lebih mudah. Pada juz satu secara garis besar berisi bagaimana cara membentuk akhlak yang baik, contoh perilaku akhlak yang baik, perilaku yang dilarang oleh agama dan contoh perilaku yang dilarang agama. Memperkenalkan Allah pada anak, memperkenalkan Nabi dan Malaikat Allah dalam artian bahwa Allah-lah yang menciptakan alam semesta ini untuk kita manfaatkan, sebagai sarana menyembah dan bertakwa kepada Allah. Menerangkan tentang taat terhadap perintah Allah dan menjauhi segala larangan-larangan Allah, menerangkan tentang akhlak kepada orang tua, bagaimana akhlak kepada guru, bagaimana sikap kita terhadap orang yang lebih muda dan lebih tua, dan bagaimana sopan santun kita ketika kita bertetangga, berteman. Pada bagian akhir juz pertama diterangkan sopan santun murid ketika dia menerima pelajaran dari guru dan diakhri dengan nasihat yang ditujukan untuk umum (masyarakat). Pada juz dua secara garis besar menerangkan tentang hakikinya al-Khalik, menerangkan tentang adab taat terhadap segala perintah Allah dan menjauhi segala larangan-larangan Allah, memberikan panduan kepada anak agar anak selalu mencontoh apa yang telah Nabi Muhammad SAW. Lakukan dalam kehidupan sehari-hari. Sebagai anak yang telah dibesarkan oleh orang tua sudah selayaknya kita 
mencintai kedua orang tua yang telah melahirkan, membesarkan serta merawat kita tanpa mengenal lelah, menggambarkan tamsil-tamsil tentang orang yang senantiasa berbuat kebaikan, dan akan mendapatkan apa yang dia inginkan, adab kepada saudara laki-laki dan perempuan untuk saling hormat menghormati dan kasih sayang antar sesama, kesederhanaan yang menjadi kunci kebahagiaan di dunia dan akhirat, menerangkan bagaimana cara kita bertetangga yang baik, kewajiban kita terhadap teman-teman kita menjadi penutup pada juz dua ini.

Pada juz tiga secara garis besar menerangkan tentang bagaimana sebaiknya kalau kita sedang berjalan, duduk, berbicara, makan, bertamu dengan sesama muslim, menengok orang yang sedang sakit, adab ketika takziyah, adab ketika kita ditimpa sebuah musibah, dan diakhiri dengan adab ketika kita akan pergi serta adab meminta sesuatu kepada Allah. Intinya pada bab tiga ini merupakan keterangan yang menerangkan tentang hubungan antara manusia dengan manusia atau ibadah ghairu mahdloh.

\section{Akhlak terhadap Allah SWT}

Telah kita ketahui bahwa Allah telah memberikan kepada kita berbagai nikmat dan anugrah yang sangat besar, maka kita wajib bersyukur atas nikmat tersebut yaitu dengan berakhlak terhadap Allah SWT dengan cara mengabdi atau beribadah hanya kepada Allah SWT, memuliakan Allah SWT; melaksanakan segala perintah-Nya dan menjauhi larangan-Nya; mencintai Allah SWT melebihi kecintaanya kepada bapak, ibu dan diri kita sendiri; berusaha dan berdoa memohon 
kepada Allah SWT agar selamanya diberi petunjuk jalan yang benar dan memohon keselamatan; memohon agar Allah SWT menjadikan anakanak perempuan yang baik dan beruntung dunia dan akhirat; dan bersyukur atas semua nikmat yang diberikan Allah SWT. Apabila kita bersyukur atas nikmat-Nya dengan melakukan perintah-Nya, maka Allah akan mencintai kita dengan menjadikan manusia lain juga mencintai kita, menjaga dari bahaya dan penyakit, dan juga akan memberikan segala sesuatu yang kita inginkan. Allah juga akan menambahi nikmat-Nya kepada kita, seperti firman Allah SWT Qs. Ibrahim ayat 7:

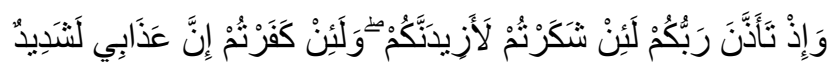

Artinya : "Dan (ingatlah juga), tatkala Tuhanmu memaklumkan; "Sesungguhnya jika kamu bersyukur, pasti kami akan menambah (nikmat) kepadamu, dan jika kamu mengingkari (nikmat-Ku), Maka Sesungguhnya azab-Ku sangat pedih".

Serta mencintai Malaikat-Malaikat Allah, para Rasul dan Nabi Allah, dan orang-orang shalih dari hamba-hamba Allah, karena sesungguhnya Allah SWT juga mencintai mereka. (Umar Baradja, 1987: $5-6)$

\section{Akhlak terhadap Rasulullah SAW}

Jika kita mencintai Allah SWT maka kitapun harus mencintai Rasul Allah yaitu dengan taat kepada Rasulullah SAW juga merupakan bagian ketaatan kepada Allah SWT, seperti firman Allah Qs. Ali Imran 31: 


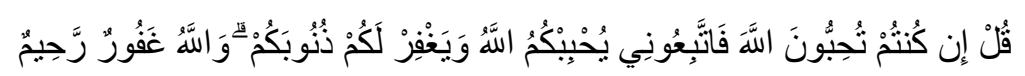

Artinya: "Katakanlah: "Jika kamu (benar-benar) mencintai Allah, ikutilah aku, niscaya Allah mengasihi dan mengampuni dosadosamu." Allah Maha Pengampun lagi Maha Penyayang."

Maka lakukanlah nasihat-nasihat Nabi yang menunjukkan kepada kebaikan dan menjauhkan kejelekan. Karena nasihat tersebut akan mendatangkan kebahagiaan. Cinta kepada Nabi Muhammad SAW tidak cukup sekedar dilahirkan dalam bentuk pengakuan kata-kata, melainkan harus dibuktikan dalam bentuk yang nyata antara lain dengan mengamalkan dan mematuhi agama Islam yang diajarkannya, baik yang terdapat dalam al-Qur'an maupun Hadis; berjuang menegakkan, mengembangkan dan membela ajaran-ajarannya, termasuk pula menjaga kemurniannya dari bid'ah dan kufarat; memuliakan Nabi Muhammad SAW dan memperbanyak shalawat kepadanya; memuliakan keluarga dan sahabat-sahabatnya; dan mengikuti nasehat-nasehatnya dan mengamalkannya dalam kehidupan.

Selain kita diwajibkan untuk memuliakan Allah SWT kita juga diwajibkan untuk memuliakan Rasulullah SAW melebihi cinta kita kepada dua orang tua dan dirinya sendiri. Karena sesungguhnya Rasulullah SAW yang mengajarkan agama Islam dan karena Rasulullah kita mengetahui Tuhan kita, juga bisa membedakan antara halal dan haram. (Umar Baradja, 1987: 9). 


\section{Signifikansi Pemikiran Umar Bin Ahmad Baradja Dalam Kitab al-} Akhlaq lil Banat dalam Pendidikan di Indonesia

Seorang anak tak ubahnya benih kecil yang membutuhkan perawatan secara ekstra, mulai dari air, suhu, udara dan sinar matahari sehingga benih itu menjadi tumbuh besar dan berkekuatan, begitu pula seorang anak pada fase pertamanya juga membutuhkan perhatian, pengawasan dan arahan secara simultan sampai pada akhirnya mereka tumbuh besar menjadi kebiasaanya semenjak kecil dengan izin Allah. Mereka kelak menjadi orang yang cinta dengan kebaikan setelah dewasa. Namun manakala pertumbuhan mereka diabaikan dengan tanpa ada perhatian sama sekali tentunya kelak mereka akan tumbuh besar menjadi orang yang sulit untuk diarahkan dan diperbaiki. Oleh karena itu hendaknya mereka perlu dididik dengan manhaj Allah yang tercantum dalam al-Qur'an dan yang sesuai dengan sunnah Nabi Muhammad SAW, dan hendaknya mereka diberi perhatian secara khusus dalam masalah pendidikan sejak tumbuhnya jari-jemari mereka pada masa perkembangannya sampai dewasa. Meski dilihat pada perkembangan selanjutnya pendidikan Islam telah mengalami proses dinamika pemikiran yang sangat luas, unsur pendidikan moral pun tak luput dari kajian pembahasan para pemikir pendidikan Islam. Pendidikan moral sendiri kemudian menjadi semacam unsur permanen dalam sistem pendidikan Islam, setidaknya dalam penetapan kurikulum maupun pemantapan visi dan misi kependidikannya. Harun Nasution berpendapat, pendidikan moral merupakan titik tekan yang sangat signifikan dalam pendidikan Islam, karena ia merupakan salah satu inti dari ajaran agama 
Islam itu sendiri, selain juga pendidikan ke-teologis-an dan keibadah-an. (Nasution, Harun, 1998:87)

Hal terpenting yang menjadi sorotan para pakar pendidikan Islam saat ini adalah tentang fenomena gejala dekadensi moral masyarakat, baik orang dewasa maupun anak-anak pelajar, seperti penyelewengan, penipuan, perampokan penindasan, saling menjegal dan saling merugikan dan masih banyak perbuatan tercela lainnya. Maka Pendidikan Islam mempunyai tugas pokok, tugas tersebut adalah membantu dan membina individu agar bertakwa dan berakhlaqul karimah, bermanfaat bagi keluarga dan masyarakat. Sebagaimana pengertian Pendidikan Islam yang dikemukakan oleh D. Marimba yaitu bimbingan atau pimpinan sadar oleh pendidikan terhadap perkembangan jasmani dan rohani peserta didik menuju terbentuknya kepribadian yang utama (Insan kamil). (D. Marimba, 1989: 19)

Agar proses pendidikan berjalan sesuai dengan yang diharapkan maka pendidikan, pengajaran dan metodenya harus diambil dari aturan dan nilainilai agama Islam. Demikian juga, kita harus mempersiapkan seorang pengajar mukmin yang memiliki nilai-nilai tersebut, sehingga dia dapat menjadi pemandu program Pendidikan Islam yang sukses, dapat menciptakan generasi muda yang berpotensi dan mempunyai kepribadian yang Islami. Untuk mencapai itu semua, maka materi yang ada dalam kitab al-Akhlaq lil Banat sangat signifikan jika dipakai sebagai acuan dalam upaya mencapai keberhasilan pendidikan. Materi yang disajikan dalam kitab ini tidak hanya mengacu pada hubungan antara manusia dengan Allah (hablumminallah), melainkan juga pada hubungan antara 
manusia satu dengan manusia lain (hablumminannas), seperti akhlaq terhadap orang tua, kerabat, tetangga, sesama teman dan juga sampai pada adab-adab berjalan, bepergian, dan lain sebagainya, telah penulis deskripsikan pada bab sebelumnya.

Metode yang di pakai oleh Umar bin Ahmad Baradja dalam kitab al-Akhlaq lil Banat antara lain: melalui teladan, nasehat, cerita atau hikayat, kebiasaan, melalui syair, dan melalui dalil naqli. Misalnya saja pendidikan melalui teladan. Keteladanan yang baik merupakan suatu keharusan dalam pendidikan, karena bagaimana mungkin seorang anak akan memiliki antusiasme untuk menjalankan sholat sedangkan dia melihat orang tuanya adalah orang yang tidak memperhatikan sholat. Bagaimana mungkin dia akan meninggalkan lagu-lagu dan lawakan, sedangkan dia melihat ibunya senantiasa memperdengarkannya. Itulah dunia anak adalah dunia meniru, ia akan meniru apa saja yang dapat ditangkap oleh indranya. Kebutuhan-kebutuhan akan figur teladan selalu ada pada manusia karena karakter manusia sebenarnya adalah senang untuk meniru. Hal ini bersumber dari kondisi mental seseorang, yang senantiasa dirinya berada dalam perasaan orang lain, sehingga dirinya meniru, ada kecenderungan anak akan meniru perilaku orang dewasa. Dan bawahan akan meniru atasannya. Untuk itu hendaklah kita mengedepankan keteladanan yang baik bagi anak-anak.

Untuk itu pemilihan metode yang tepat akan sangat penting diterapkan dalam Pendidikan Islam guna mewujudkan tujuan pendidikan terciptanya insan kamil yang berkepribadian shalih-shalihah. Dalam proses pembentukan kepribadian anak, diperlukan strategi dan metode 
yang tepat. Dan keberadaan kitab ini sangatlah signifikan dalam upaya pencapaian terbentuknya generasi muda yang sesuai dengan tujuan umat islam. Tujuan pendidikan bukanlah suatu benda yang berbentuk tetap dan statis tetapi tujuan itu merupakan keseluruhan dari kepribadian seseorang yang berkenaan dengan seluruh aspek kehidupannya. Kata Hasan Langgulung: "Berbicara tentang tujuan pendidikan tidak terlepas dari pembahasan tentang tujuan hidup manusia. Oleh karena itu pendidikan hanyalah suatu alat yang digunakan manusia untuk memelihara kelanjutan hidupnya, baik sebagai individu atau masyarakat. (Hasan Langgulung, 1995: 55).

Tujuan pendidikan tersebut tidak jauh berbeda dengan tujuan pendidikan yang ada dalam kitab al-Akhlaq lil Banat walaupun dalam penyampaiannya berbeda. Tujuan dalam al-Akhlaq lil Banat upaya pembentukan kepribadian individu dan kepribadian sosial yang baik, seperti contohnya akhlak minum, makan dan tidur akan membentuk kepribadian individu yang baik, sedang kepribadian sosial dengan menanamkan akhlak terhadap orang tua, guru, saudara, tetangga, dan terhadap teman, sehingga kitab al-Akhlaq lil Banat sangatlah signifikan dipakai dalam proses pendidikan di Indonesia.

\section{Relevansi Pemikiran Umar Bin Ahmad Baradja Dalam Kitab al-} Akhlaq lil Banat dalam Pendidikan di Indonesia

Penanaman akhlak menjadi prioritas utama, karena harapan terbesar bertumpu pada anak, dimana mereka adalah penerus perjuangan, pewaris dan pembawa nama orang tua dan keluarga, berkibar di langit 
dan semerbak harum mewangi, ataukah anak yang akan mencoreng muka orang tua dan keluarga oleh karena kebejatan akhlak yang dimiliki. Anak merupakan amanat belahan hati yang suci, mutiara paling berharga yang masih netral dan belum terbentuk, oleh karena itu dia siap dibentuk dan dibawa kemanapun dia akan dibawa. Seperti yang telah ada dalam kitab al-Akhlaq lil Banat bahwa jika seorang anak dibiasakan dan diajari halhal yang baik, maka dia akan tumbuh dengan baik dan tentu akan menjadi orang yang bahagia di dunia dan akhirat. Begitu juga sebaliknya, jika dibiasakan dan diajari hal-hal yang buruk, diabaikan layaknya binatang tentu dia akan menderita dan rusak, untuk itu membimbing dan menanamkan akhlak yang terpuji kepada anak merupakan cara pendidikan akhlak yang berhasil, dengan kata lain yaitu: "Adab bisa berguna selagi anak dalam kedinian dan tiada lagi berguna baginya setelah itu, ibarat ranting kecil akan lurus jika diluruskan, tiada lagi lurus jika ia menjadi batang yang kaku".

Pendidikan akhlak untuk generasi sekarang ini juga dihadapkan pada persoalan-persoalan yang cukup kompleks, yakni persoalan reformasi dan globalisasi menuju masyarakat Indonesia baru. Tantangan yang dihadapi sekarang adalah bagaimana upaya untuk membangun paradigma baru Pendidikan Islam, visi, misi, dan tujuan, yang didukung dengan sistem kurikulum atau materi pendidikan, manajemen dan organisasi, metode pembelajaran untuk dapat mempersiapkan manusia yang berkualitas, bermoral tinggi dalam menghadapi perubahan masyarakat global yang begitu cepat, sehingga produk Pendidikan Islam tidak hanya melayani dunia modern, tetapi mempunyai pasar baru atau 
mampu bersaing secara kompetitif dan proaktif dalam dunia masyarakat modern, global dan informasi.

Perubahan yang perlu dilakukan Pendidikan Islam, yaitu pertama, membangun sistem Pendidikan Islam yang mampu mengembangkan sumber daya manusia yang berkualitas agar mampu mengantisipasi kemajuan iptek untuk menghadapi tantangan dunia global menuju masyarakat Indonesia baru yang dilandasi dengan nilai-nilai ilahiyah, kemanusiaan (insaniyah), dan masyarakat, serta budaya. Kedua, menata manajemen Pendidikan Islam dengan berorientasi pada manajemen berbasis sekolah agar mampu menyerap aspirasi masyarakat, dapat mendayagunakan potensi masyarakat dalam rangka,penyelenggaraan Pendidikan Islam yang berkualitas. Serta ketiga, meningkatkan demokratisasi penyelenggaraan Pendidikan Islam secara berkelanjutan dalam upaya memenuhi kebutuhan masyarakat agar dapat menggali serta mendayagunakan potensi masyarakat. Namun dalam hal ini, kitab alAkhlaq lil Banat kurang efesien jika dipakai dalam proses pendidikan akhlaq anak, karena adanya kemjuan teknologi zaman, sehingga dalam hal ini diperlukan pemikiran pembaharuan lagi untuk penyesuaian dengan kemajuan zaman globalisasi. Proses pendidikan akhlaq adalah usaha sadar dan tidak sadar yang dilakukan oleh seorang pendidik untuk membentuk tabiat yang baik pada seorang anak didik, sehingga terbentuk manusia yang taat kepada Allah.

Pembentukan tabiat ini dilakukan oleh pendidik secara kontinue dengan tidak ada paksaan dari pihak manapun. Pendidikan akhlaq pada hakekat keberadaannya sangatlah urgen di Indonesia, pendidikan yang 
bertujuan membentuk pribadi muslim yang seutuhnya, mengembangkan seluruh potensi manusia baik dari segi rohaniah atau jasmaniah, menumbuhsuburkan hubungan harmonis setiap pribadi dengan Allah, sesama dan juga semesta alam. Agar peserta didik dapat mencapai tujuan Pendidikan Islam tersebut, maka eksistensi lembaga pendidikan di Indonesia harus menyusun rancangan program pendidikan yang dijabarkan dalam kurikulum yang berorientasi pada tercapainya hubungan transenden antara manusia dengan sang khaliq sesuai dengan fitrah manusia sebagai abdullah, dan tercapainya hubungan antroposentris antara sesama manusia dan antara manusia dengan makhluk lain, sesuai dengan fungsi manusia sebagai khalifah (pemimpin) di muka bumi.

Relevansi kitab al-Akhlaq lil Banat terhadap Pendidikan Islam di Indonesia sangatlah berkesinambungan, karena baik dari segi materi isi kitab, metode yang dipakai dan tujuan pendidikan dalam kitab ini sangatlah cocok untuk dipakai oleh lembaga-lembaga Pendidikan Islam di Indonesia, terutama yang telah dipakai oleh lembaga pendidikan non formal. Sehingga akan terciptalah generasi Islam yang berkualitas yang sesuai dengan tujuan Pendidikan Islam. Dalam kitab ini Umar Bin Ahmad Baradja banyak menjelaskan akhlak mahmudah, seperti contoh penanaman rasa malu, hal ini akan terwujud apabila kita menjaga pandangan dari sesuatu yang tidak halal, menghargai setiap orang yang memiliki keutamaan dan menghargai orang-orang yang patut dihargai menurtu derajat mereka, seperti orang tua, guru, serta orangorang yang lebih tua. Kitab ini juga menjelaskan akhlak mazmumah, akhlak tercela 
yang harus ditinggalkan, seperti contoh menghindari sifat dusta, karena jika sifat dusta ini telah merajalela di masyarakat, maka tidak bisa diharapkan terwujudnya keamanan dan kedamaian dalam kehidupan bersama. Maka dari itu kitab ini sangat urgen dalam proses penanaman akhlaq anak dalam rangka pembentukan pribadi anak yang shalih dan shalihah. Karena jika bumi ini diwariskan kepada generasi-generasi yang tidak bertanggungjawab, yang terjadi hanyalah exploitasi alam, kemaksiatan dan kemungkaran. Hal ini akan dapat membawa malapetaka dan nestapa di muka bumi.

Implikasi Pemikiran Umar Bin Ahmad Baradja Dalam Kitab Al Akhlaq Lil Banat dalam Pendidikan di Indonesia

Kitab al-Akhlaq lil Banat ini telah digunakan di beberapa lembaga pendidikan non formal, seperti di Madrasah Banat dan di beberapa pondok pesantren terutama di jawa, khususnya di pondok pesantren banat al-Badriyah Mranggen, Pondok Pesantren Banat Kudus, Madrasah Diniyah Islahiyyah Mranggen dan pondok pesantren putri Bustanu 'Usyaqil Qur'an Bener. Bahkan kitab ini telah dimasukkan dalam kurikulum, karena kitab ini tidak hanya berisi tentang pendidikan akhlak yang mengarah pada hubungan dengan Sang Pencipta namun juga hubungan terhadap Orang Tua, Guru, saudara, tetangga, dan teman, serta menjelaskan tata cara bertamu yang baik dan makan minum yang baik. Adapun hal-hal positif yang diperoleh oleh peserta didik atau santri yang mempelajari dan mengindahkan kitab ini diantaranya adalah perubahan sikap terhadap orang-orang disekitarnya, perubahan perilaku dalam 
bertindak atau melakukan aktifitas. Dengan mempunyai akhlak terpuji dan menjauhkannya dari perilaku yang buruk, sehingga setiap peserta didik atau santri dapat hidup dengan aman dan tentram. Akhlak terpuji tersebut diantaranya terciptanya kerja sama dan solidaritas yang baik, mempererat tali silaturahmi, bertamu dan berkunjung dengan baik dan sopan, berbicara dengan sopan, saling memuliakan dan saling menghormati, serta menjauhi perilaku buruk atau tercela seperti mengunjing, mengumpat, menfitnah, dan mengambil hak temannya.

Dalam penanaman akhlak terpuji tersebut perlu adanya loyallitas terhadap dua sumber pokok ajaran Islam, yaitu al-Qur'an dan Hadis, serta sifat konsistensi dan kesungguhan dalam penerapan kehidupan sehari-hari. Ada juga dari sebagian peserta didik yang tidak mengindahkan kitab ini dan tidak menyadari akan urgennya pendidikan akhlak, hal tersebut akan menimbulkan dekadensi moral pada generasi Islam, yaitu diantaranya merebaknya peserta didik atau santri yang mengambil uang temannya, menfitnah temannya, menggunjing, membuat kegaduhan, berburuk sangka dan berdusta baik kepada guru ataupun temannya.

Maka dalam rangka penerapan kitab akhlak ini kepada peserta didik atau santri, selain harus menekankan sifat loyalitas, konsisten dalam berakhlaq terpuji, seorang guru (ustadh dan ustadhah) dan pengurus juga harus memberikan keteladanan yang tepat serta harus kita tunjukkan tentang bagaimana kita harus bersikap, bagaimana kita harus menghormati dan seterusnya. Kalau kita ingin dihormati oleh orang lain, tentulah harus kita awali dari kita sendiri untuk berbuat baik kepada 
sesama dan berbakti kepada kedua orang tua kita. Maka dengan mengawalinya demikian, niscaya orang lain pun akan menghormati kita dan anak-anak pun berbakti kepada kita. Jadi pembelajaran kitab akhlak ini tidak hanya dalam kelas saja, yaitu dengan metode ceramah namun juga perlu diterapkan metode keteladanan, nasehat dan kebiasaan.

Maka dengan usaha pembiasaan pada diri secara dini dan konsisten, lebih bisa diharapkan akhlakul karimah akan benar-benar tumbuh pada diri anak sehingga apa yang diharapkan oleh kita akan terwujud yakni harapan yang nantinya mempunyai sebuah keluarga yaitu keluarga yang dipimpin oleh seorang kepala keluarga yang shalih didampingi oleh seorang istri yang shalihah dan dihiasi pula putra-putri yang shalih dan shalihah.

\section{Kesimpulan}

Berdasarkan uraian dalam bab-bab yang telah lalu, maka penulis dapat mengemukakan kesimpulan sebagai berikut, yaitu pertama, materi akhlak dalam kitab al-Akhlaq lil Banat meliputi hubungan transedental antara menusia dengan Sang Khalik, sesuai penciptaan manusia sebagai Abdullah, dan hubungan antroposentris antar sesama manusia, sesuai dengan fungsinya sebagai kholifah fil ard. Dalam mensukseskan proses pendidikan akhlak untuk membentuk pribadi anak perlu penerapan metode, diantaranya melalui teladan, nasehat, kisah atau cerita, kebiasaan, menggunakan dalil naqli, dan menggunakan syair. Metodemetode tersebut sangat efektif dan lazim untuk diterapkan dalam proses pendidikan akhlaq di indonesia. 
Kedua, dalam membentuk pribadi anak yang shalih-shalihah, peran keluarga dan masyarakat sangatlah berpengaruh dalam kemampuan serta kesiapan orang tua dan lingkungan masyarakat dalam mengantarkannya menjadi insan shalih-shalihah. Dengan mengacu pada sebuah kurikulum untuk berlanjutnya proses pendidikan akhlak anak dalam upaya pembentukan pribadi anak yang shalihah. Maka Kitab alAkhlaq lil Banat terhadap Pendidikan akhlak anak di Indonesia sangatlah berkesinambungan, karena baik dari segi materi isi kitab, metode yang dipakai dan tujuan pendidikan dalam kitab ini sangatlah cocok untuk dipakai oleh lembaga-lembaga Pendidikan Islam di Indonesia. Sehingga akan terciptalah generasi Islam yang berkualitas yang sesuai dengan tujuan Pendidikan Islam.

\section{Daftar Pustaka}

Abdurrahman, Jamal. 2003. Atfal al-Muslim, Kaifa Rabaahum al-Nabiy al-Amin?, terjemah oleh Jujuk Najibah Ardianingsih, Pendidikan Ala Kanjeng Nabi. Yogyakarta: Mitra Pustaka.

al-Barry, M. Dahlan. 1994. Kamus Ilmiah Populer. Surabaya: Arloka.

al-Kisah. 2007. NO.07/V11/26 Maret-8 April.

Baradja, Umar. 1987. al-Akhlaq lil Banat, Surabaya: CV. Ahmad Nabhan, Jilid I, II \& III.

D. Marimba, Ahmad. 1989. Pengantar Pendidikan Islam. Bandung: alMa'rifat Rosda Karya.

Depdikbud. 1990. Kamus BBI. Jakarta: Balai Pustaka.

Fajar, A. Malik. 1999. Reorientasi Pendidikan Islam. Jakarta: Fajar Dunia, Cet I.

Hadi, Sutrisno. 1991. Metodologi Research. Yogyakarta: Andi Offset, Jilid 1.

Langgulung, Hasan. 1995. Manusia dan Pendidikan, Suatu Analiasa Psikologi dan Pendidikan. Jakarta: al-Husna Zikra.

Nasution, Harun. 1998. Islam Rasional, Bandung: Mizan. 
Mudarrisa: Jurnal Kajian Pendidikan Islam, Vol. 6, No.2, Desember 2014: 251-276

Nata, Abuddin. 1997. Filsafat Pendidikan Islam. Jakarta: Logos Wacana Ilmu.

. 2003. Manajemen Pendidikan Mengatasi Kelemahan Pendidikan Islam di Indonesia, Jakarta: Kencana.

Nazir, Muhammad. 1988. Metode Penelitain. Jakarta: Galia Indonesia.

Razak, Nasrudin. Dinul Islam. Bandung: al-Ma'arif.

Sulaiman, M. Subhi. Fannu Tarbiyah al-Banat, terjemah oleh Akhmad Sodiqin, Lc, Sholihah Kiat Mendidik Anak Perempuan dalam Islam. Semarang: Pustaka Adnan.

Toha, Chabib. 1996. Kapital Selekta Pendidikan Islam. Yogyakarta: Pustaka Pelajar.

Uhbiyati, Nur. 1998. Ilmu Pendidikan Islam. Bandung: Pustaka Setia. Zaini, Syahminan. 1996. Penyakit Rohani, Pengobatannya. Jakarta: Kalam Mulia. 